\title{
Modeling of gaseous methylamines in the global atmosphere: impacts of oxidation and aerosol uptake
}

\author{
F. Yu and G. Luo \\ Atmospheric Sciences Research Center, State University of New York, 251 Fuller Road, Albany, New York 12203, USA \\ Correspondence to: F. Yu (fyu@albany.edu)
}

Received: 2 June 2014 - Published in Atmos. Chem. Phys. Discuss.: 2 July 2014

Revised: 17 October 2014 - Accepted: 18 October 2014 - Published: 27 November 2014

\begin{abstract}
Gaseous amines have attracted increasing attention due to their potential role in enhancing particle nucleation and growth and affecting secondary organic aerosol formation. Here we study with a chemistry transport model the global distributions of the most common and abundant amines in the air: monomethylamine (MMA), dimethylamine (DMA), and trimethylamine (TMA). We show that gas phase oxidation and aerosol uptakes are dominant sinks for these methylamines. The oxidation alone (i.e., no aerosol uptake) leads to methylamine lifetimes of $5-10 \mathrm{~h}$ in most parts of low and middle latitude regions. The uptake by secondary species with uptake coefficient $(\gamma)$ of 0.03 (corresponding to the uptake by sulfuric acid particles) reduces the lifetime by $\sim 30 \%$ over oceans and much more over the major continents, resulting in a methylamine lifetime of less than 1-2 $\mathrm{h}$ over central Europe, eastern Asia, and eastern US. With the estimated global emission flux, from the literature, our simulations indicate that [DMA] in the model surface layer over major continents is generally in the range of $0.1-2 \mathrm{ppt}$ (parts per trillion) when $\gamma=0.03$ and $0.2-10 \mathrm{ppt}$ when $\gamma=0$, and decreases quickly with altitude. [DMA] over oceans is below $0.05 \mathrm{ppt}$ and over polar regions it is below $0.01 \mathrm{ppt}$. The simulated [MMA] is about a factor of $\sim 2.5$ higher while [TMA] is a factor of $\sim 8$ higher than [DMA]. The modeled concentrations of methylamines are substantially lower than the limited observed values available, with normalized mean bias ranging from $-57(\gamma=0)$ to $-88 \%$ $(\gamma=0.03)$ for MMA and TMA, and from $-78(\gamma=0)$ to $-93 \%(\gamma=0.03)$ for DMA.
\end{abstract}

\section{Introduction}

In recent years, gaseous amines have attracted increasing attention due to theoretical, laboratory, and field measurements indicating that amines may considerably enhance particle formation and growth (Kurtén et al., 2008; Nadykto et al., 2011, 2014; Almeida et al., 2013; Berndt et al., 2010; Zhao et al., 2011; Erupe et al., 2011; Chen et al., 2012; Wang et al., 2010a; Yu et al., 2012) and affect secondary organic aerosol (SOA) formation (De Haan et al., 2009, Myriokefalitakis et al., 2010; Williams et al., 2010). Amines are organic compounds and derivatives of ammonia wherein one or more hydrogen atoms are replaced by a substituent such as an alkyl or aryl group. About 150 amines have been identified in the atmosphere; the most common and abundant amines being the low-molecular-weight methylamines such as monomethylamine (MMA), dimethylamine (DMA), and trimethylamine (TMA) (Ge et al., 2011a). Concentrations of amines can exceed several parts-per-billion by volume (ppbv) near their sources (Ge et al., 2011a; Schade and Crutzen, 1995) but are expected to be low farther away as a result of their short lifetime due to oxidation by OH (Carl and Crowley, 1998) and uptake by particles (Qiu and Zhang, 2013).

While amines are stronger bases than ammonia and ternary $\mathrm{H}_{2} \mathrm{SO}_{4}-\mathrm{H}_{2} \mathrm{O}$-amine clusters are more stable (Kurtén et al., 2008; Nadykto et al., 2011, 2014; Almeida et al., 2013), the relative role of amines versus ammonia in enhancing particle formation in the atmosphere is yet to be determined (Zollner et al., 2012). This is because the concentration of amines in the atmosphere is generally much lower than that of ammonia (by $2-3$ orders of magnitude or more) (Ge et al., 2011a; Hanson et al., 2011). Recent measurements taken during the CLOUD (Cosmics Leaving Outdoor Droplets) chamber experiments at CERN (European Council for Nuclear Re- 
search; Almeida et al., 2013) indicate that a [DMA] of above $\sim 5$ parts-per-trillion by volume (pptv) enhances nucleation substantially, but enhancement drops significantly as [DMA] decreases below that level.

In order to determine the contribution of ternary nucleation involving amines to atmospheric particle production, it is critical to know the concentrations of key amines and their variations in the atmosphere. Due to their high reactivity and low concentrations, measurements of gaseous amines in the background atmosphere are very limited (Ge et al., 2011a). Several studies show [DMA] is below 1 pptv in urban areas (Grönberg et al., 1992a, b) while a couple of other studies observed [DMA] around a few pptv in rural and coastal areas (Hanson et al., 2011; VandenBoer et al., 2011, 2012; Van Neste et al., 1987; Gibb et al., 1999). Although TMA is generally more abundant (Ge et al., 2011a), the concentration of TMA needed to substantially enhance nucleation remains to be studied.

In addition to in situ measurements, numerical modeling is also needed to integrate the various processes controlling amine concentrations and ultimately assess the impact of amines on global nucleation, aerosol properties, and climate. While limited measurements of amines are available, modeling of global amines is basically nonexistent. Myriokefalitakis et al. (2010) explored the potential contribution of amines emitted from oceans to SOA formation, assuming total amine emissions to be one-tenth of the oceanic ammonia emissions. Myriokefalitakis et al. (2010) neither considered amines from continental sources nor presented concentrations of gaseous amines over oceans. In the present work, we aim to simulate the global distributions of gaseous amines in the air with a global chemistry transport model. The key processes controlling amine concentrations (including emission, transport, oxidation, deposition, and aerosol uptake) are considered and the simulated results are compared to the limited measurements available.

The methods of the present study (including sources, sinks, and model representation) are described in Sect. 2. The modeling results, comparisons with measurements, and sensitivity studies are given in Sect. 3. Section 4 contains the summary and discussion.

\section{Methods}

\subsection{Sources and fluxes}

Amines are ubiquitous atmospheric organic bases, and are emitted from a wide range of sources including animal husbandry, biomass burning, motor vehicles, industry, meat cooking, fish processing, sewage treatment and waste incineration, protein degradation, vegetation, soils, and ocean organisms (Ge et al., 2011a). On a global scale, little is known about the flux of most amines, especially various aromatic amines (Ge et al., 2011a). Among about 150 amines identified in the atmosphere, methylamines (MMA, DMA, and TMA) are most common and abundant. Schade and Crutzen (1995) estimated the global emission fluxes of MMA, DMA, and TMA to be $83 \pm 26,33 \pm 19$, and $169 \pm 33 \mathrm{Gg} \mathrm{Nyr}^{-1}$, respectively. The total methylamine flux of $285 \pm 78 \mathrm{Gg} \mathrm{N} \mathrm{yr}^{-1}$ is more than 2 orders of magnitude smaller than the estimated global ammonia flux of $50000 \pm 30000 \mathrm{Gg} \mathrm{N} \mathrm{yr}^{-1}$ (Schade and Crutzen, 1995).

\subsection{Sinks}

The main sinks of amines emitted into the atmosphere include dry and wet deposition, gas phase reactions, and heterogeneous uptake. Since most of the amines are highly soluble, wet deposition is an important process to bring amines in the air to the surface. As organic compounds, gaseous amines undergo oxidation reactions with $\mathrm{OH}, \mathrm{NO}_{\mathrm{x}}$, or $\mathrm{O}_{3}$ (Nielsen et al., 2012; Lee and Wexler, 2013). The lifetimes of amines with respect to $\mathrm{OH}$ oxidation are typically a couple of hours, much shorter than those by reactions with $\mathrm{O}_{3}$ and $\mathrm{NO}_{\mathrm{x}}$. The gaseous methylamines, which are strong bases, may also undergo rapid acid-base reactions to form salt particles in the presence of inorganic acids $\left(\mathrm{HCl}, \mathrm{HNO}_{3}, \mathrm{H}_{2} \mathrm{SO}_{4}\right.$ ) (Murphy et al., 2007). In addition, amines may react with organic acids to form amides (Barsanti and Pankow, 2006). A detailed discussion of the chemistry of amines in the atmosphere can be found in several recent review articles (Nielsen et al., 2012; Lee and Wexler, 2013).

Owing to their high aqueous solubility and strong basicity, gaseous amines can efficiently enter into a particulate phase via direct dissolution and acid-base reactions. The importance of amines with regard to gas/particle partitioning has been supported by the reactive uptake of TMA into ammonium nitrate particles (Lloyd et al., 2009) and amine exchange into ammonium bisulfate and nitrate nuclei (Bzdek et al., 2011). Laboratory studies show that heterogeneous reactions of gaseous alkylamines on $\mathrm{H}_{2} \mathrm{SO}_{4}$ nanoparticles resulted in the formation of alkyl ammonium sulfates and particle growth (Wang et al., 2010a, b). It has also been observed that methylamine could react with glyoxal in drying cloud droplets to form SOA (De Haan et al., 2009) and stable aminium salts could be formed by amine and organic acids in the aerosols (Williams et al., 2010). The thermodynamic properties of amines that control their partitioning between the gas and the particle phase in the atmosphere are examined in a review paper (Ge et al., 2011b). An overview of laboratory progress in the multiphase chemistry of amines can be found in Qiu and Zhang (2013).

\subsection{Model representation}

A numerical model is needed to integrate the various processes influencing the concentrations of amines in the atmosphere. In the present study we employ GEOS-Chem, a global 3-D model of atmospheric composition driven by 
Table 1. Calculated global annual mean emissions, sinks, and burdens of ammonia, MMA, DMA, and TMA. Sinks and burdens under four different uptake coefficients $(\gamma=0.03,0.01,0.001$, and 0$)$ are given.

\begin{tabular}{lcccccc}
\hline & $\gamma$ & $\begin{array}{c}\text { Emission } \\
\left(\mathrm{Gg} \mathrm{N} \mathrm{yr}^{-1}\right)\end{array}$ & $\begin{array}{c}\text { Oxidation } \\
\left(\mathrm{Gg} \mathrm{N} \mathrm{yr}^{-1}\right)\end{array}$ & $\begin{array}{c}\text { Uptake } \\
\left(\mathrm{Gg} \mathrm{N} \mathrm{yr}^{-1}\right)\end{array}$ & $\begin{array}{c}\text { Dry and wet deposition } \\
\left(\mathrm{Gg} \mathrm{N} \mathrm{yr}^{-1}\right)\end{array}$ & $\begin{array}{c}\text { Burden } \\
(\mathrm{Gg} \mathrm{N})\end{array}$ \\
\hline Ammonia & & $5.8 \times 10^{4}$ & $-4.9 \times 10^{2}$ & $-3.8 \times 10^{4}$ & $-1.9 \times 10^{4}$ & 79.9 \\
MMA & 0.03 & 96.2 & -17.2 & -65.8 & -13.2 & 0.07 \\
MMA & 0.01 & 96.2 & -28.4 & -48.1 & -19.8 & 0.12 \\
MMA & 0.001 & 96.2 & -51.7 & -14.2 & -30.4 & 0.22 \\
MMA & 0 & 96.2 & -61.8 & 0.0 & -34.4 & 0.27 \\
\hline DMA & 0.03 & 38.3 & -12.2 & -21.9 & -4.2 & 0.03 \\
DMA & 0.01 & 38.3 & -17.3 & -15.0 & -6.0 & 0.05 \\
DMA & 0.001 & 38.3 & -25.9 & -3.8 & -8.6 & 0.08 \\
DMA & 0 & 38.3 & -28.9 & 0.0 & -9.3 & 0.08 \\
\hline TMA & 0.03 & 196.0 & -49.8 & -122.0 & -23.9 & 0.24 \\
TMA & 0.01 & 196.0 & -75.4 & -85.7 & -34.7 & 0.38 \\
TMA & 0.001 & 196.0 & -122.0 & -23.0 & -50.9 & 0.63 \\
TMA & 0 & 196.0 & -140.0 & 0.0 & -56.2 & 0.72 \\
\hline
\end{tabular}

assimilated meteorological data from the NASA Goddard Earth Observing System 5 (GEOS-5) (e.g., Bey et al., 2001). The GEOS-Chem model has been developed and used by many research groups and contains a number of state-ofthe-art modules treating various chemical and aerosol processes with up-to-date key emission inventories (for details, see the model web page http://geos-chem.org/). Global ammonia emissions are based on the inventory developed by the Global Emission Inventory Activity (GEIA) (Bouwman et al., 1997) and national emission estimates are used for the US (NEI05), Canada (CAC), Europe (EMEP), and eastern Asia (Streets2000). While ammonia is simulated in detail in GEOS-Chem, amines are not considered prior to this study. Here, to represent gas phase methylamines, we add three tracers (MMA, DMA, and TMA) in GEOS-Chem v8.3.2 with an advanced particle microphysics (APM) model incorporated (Yu and Luo, 2009).

There exist large uncertainties in the estimated emission fluxes of amines, and detailed emission inventories of amines from various sources are currently not available. In the present study, we use the ratios of methylamines to ammonia fluxes given in Schade and Crutzen (1995) but approximate the spatial distribution and seasonal variations of amine emissions following those of ammonia. Such a first-order approximation enables us to simulate the typical concentrations of amines in the global atmosphere. The dry and wet deposition, as well as horizontal and vertical transport of amines, is also considered in GEOS-Chem, following the approaches for ammonia.

In the present study, we only take into account the oxidation of methylamines by $\mathrm{OH}$ as the oxidation of amines by $\mathrm{NO}_{3}$ and $\mathrm{O}_{3}$ is much smaller. There have been limited measurements of the kinetics of $\mathrm{OH}$ reactions with simple alkyl amines (Ge et al., 2011a;
Nielsen et al., 2012; Lee and Wexler, 2013). In this study we use the reaction coefficients reported by Carl and Crowley (1998): $1.79 \times 10^{-11}, 6.49 \times 10^{-11}$, and $3.58 \times 10^{-11} \mathrm{~cm}^{3}$ molecule $\mathrm{s}^{-1}$, for MMA, DMA, and TMA, respectively. For comparison, the reaction coefficient of $\mathrm{NH}_{3}$ with $\mathrm{OH}$ is $1.6 \times 10^{-13} \mathrm{~cm}^{3}$ molecule ${ }^{-1} \mathrm{~s}^{-1}$ (Atkinson et al., 1997), more than 2 orders of magnitude smaller. The uptake of amines by particles is considered, using the particle surface areas calculated from particle size distributions predicted by GEOS-Chem APM. One key uncertainty about the heterogeneous uptake is the uptake coefficient $(\gamma)$, defined as the ratio of gas surface collisions that result in loss of the amines onto the surface to the total gas surface collisions. Lloyd et al. (2009) reported a reactive uptake coefficient of $2 \times 10^{-3}$ for the uptake of TMA by ammonium nitrate aerosols at $20 \% \mathrm{RH}$ (relative humidity). Wang et al. (2010b) studied the uptake of alkylamines (MMA, DMA and TMA) on sulfuric acid surfaces and found uptake coefficients in the range of $(2.0-4.4) \times 10^{-2}$. In a laboratory study of the heterogeneous reactions between alkylamines (MMA, DMA and TMA) and ammonium salts (ammonium sulfate and ammonium bisulfate), Qiu et al. (2011) found that, for the three alkylamines, the initial uptake coefficients $\left(\gamma_{0}\right)$ range from $2 \times 10^{-2}$ to $3.4 \times 10^{-2}$ and the steady-state uptake coefficients $\left(\gamma_{\mathrm{ss}}\right)$ range from $6.0 \times 10^{-3}$ to $2.3 \times 10^{-4}$ and decrease as the number of methyl groups on the alkylamine increases. It is clear from these laboratory studies that the values of $\gamma$ depend on the particle compositions. The secondary components of particles in the atmosphere (sulfate, nitrate, SOA, and ammonium), which are likely to play an important role in the uptake of amines, are generally internally mixed. The uptake coefficients of amines by these mixed particles, under different atmospheric conditions (especially RH), are not yet known. In the present study, 
the sensitivity of predicted amine concentrations to $\gamma$ values ranging from 0 (no uptake) to 0.03 is studied. We assume no uptake of amines by pure dust, black carbon, and primary organic carbon. We do not consider the uptake of amines by sea salt particles due to lack of information with regard to the uptake coefficients. The gaseous phase reactions of amines with $\mathrm{HNO}_{3}, \mathrm{HCl}$, and organic acids are not considered, since oxidation and aerosol uptake likely dominate the loss of amines. In the present study, we also do not consider the re-evaporation of amines after uptake by secondary particles as laboratory studies indicate that amines can react with various acids to form stable aminium salts (e.g., Qiu and Zhang, 2013). For example, recent laboratory measurements show that sulfate particles act as an almost perfect sink (negligible evaporation) for amines (Almeida et al., 2013).

\section{Results}

The results presented below are based on a $1 \mathrm{yr}$ simulation (October 2005-December 2006, with the first 3 months as spin up) using GEOS-Chem v8.3.2 + APM, with the kinetic condensation of low, volatile secondary organic gases from successive oxidation aging taken into account (Yu, 2011). The horizontal resolution (latitude by longitude) is $2^{\circ} \times 2.5^{\circ}$ and there are 47 vertical layers in the model (surface to $0.01 \mathrm{hpa}$ ).

Table 1 shows global annual mean emissions, sinks (due to oxidation, uptake, and dry/wet deposition), and burdens for ammonia, MMA, DMA, and TMA. Sinks and burdens of methylamines under four different uptake coefficients $(\gamma=0.03,0.01,0.001$, and 0$)$ are given. The global ammonia emission flux for 2006 based on GEOS-Chem is $5.8 \times 10^{4} \mathrm{Gg} \mathrm{Nyr}^{-1}$, about $15 \%$ higher than the estimation of Schade and Crutzen (1995). The MMA, DMA, and TMA emissions fluxes assumed in the present study (96.2, 38.3, and $196.0 \mathrm{Gg} \mathrm{Nyr}^{-1}$, respectively) are also $15 \%$ higher, as the same ratios of methylamines to ammonia emission fluxes given in Schade and Crutzen (1995) are used. The $15 \%$ difference is within the estimated methylamine emission uncertainty of $\sim 30 \%$ (Schade and Crutzen, 1995).

As an example for the spatial distribution of emission fluxes, Fig. 1 presents the horizontal distributions of DMA emissions assumed in the present study. As mentioned earlier, we approximate the spatial distribution and seasonal variations of methylamine emissions following those of ammonia. Again, this should be considered as a first-order approximation, as the emission rates of amines from various sources may be quite different from those of ammonia. With the understanding of this limitation, we can see in Fig. 1 that DMA emission rates are in the range of $\sim 0.2-10 \mathrm{~kg} \mathrm{~N} \mathrm{~km}^{-2} \mathrm{yr}^{-1}$ over major continents and below $0.2 \mathrm{~kg} \mathrm{~N} \mathrm{~km}^{-2} \mathrm{yr}^{-1}$ over oceans. For MMA and TMA, the absolute emission fluxes are a factor of 2.5 and 5.1 higher (Table 1). In Fig. 1 we also marked the locations of sites

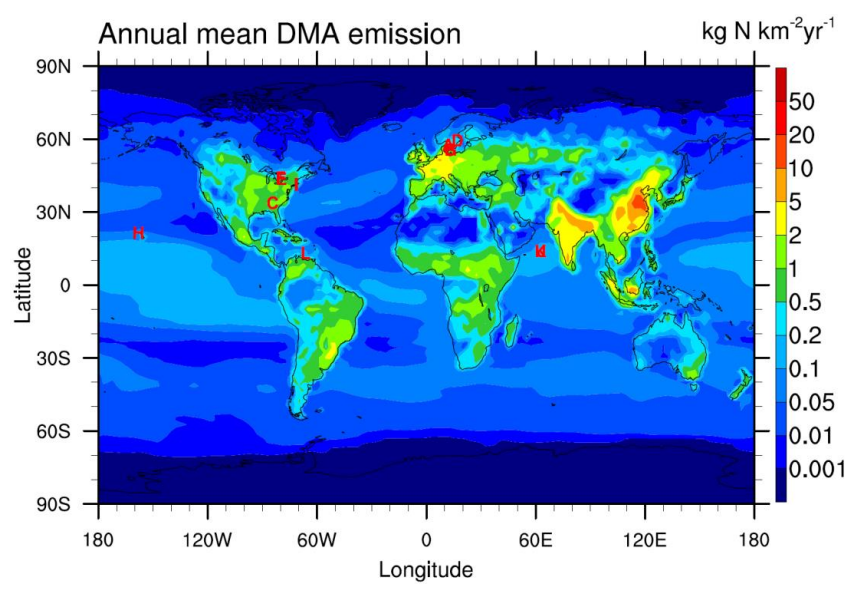

Figure 1. Horizontal distributions of annual mean DMA emissions assumed in the present study.

where some kind of methylamine measurements are available, as summarized in Table 2. It should be noted that sites A, B, D, and G are close to each other and overlap in Fig. 1. Similarly, sites E and F overlap in Fig. 1. Sites J and K are the same location but measurements were taken during different time periods. A comparison of simulated and observed methylamine concentrations is discussed later.

It can be seen from Table 1 that gas phase oxidation and aerosol uptakes are dominant sinks for methylamines (Table 1). As expected, the uptake sinks are sensitive to $\gamma$ when $\gamma>\sim 0.001$ and the oxidation becomes more important when $\gamma$ is smaller. The change of $\gamma$ from 0.03 to 0.001 increases the modeled global burdens of methylamines by a factor of $\sim 2.7$. Further decrease of $\gamma$ from 0.001 to 0 has relatively small effects on the predicted burdens. Dry and wet deposition accounts for $11-14 \%$ and $25-35 \%$ of the sinks when $\gamma=0.03$ and $\gamma=0$, respectively. The global burdens of MMA, DMA, and TMA are respectively from 0.07 to $0.27 \mathrm{GgN}, 0.03$ to $0.08 \mathrm{Gg} \mathrm{N}$, and 0.24 to $0.72 \mathrm{Gg} \mathrm{N}$ as $\gamma$ changes from 0.03 to 0 . The ratios of ammonia burden to that of methylamines (MMA + DMA + TMA) range from $74(\gamma=0)$ to $236(\gamma=0.03)$. The burdens are roughly but not strictly proportional to emission fluxes because of the difference in the oxidation rates and deposition velocities (which also depend on molecular weights).

Figure 2 shows the simulated horizontal distributions of the annual mean DMA oxidation and uptake lifetime ( $\tau$, calculated as the ratio of the burden in each gird box to the corresponding sinks associated with oxidation and uptake) and concentration ([DMA]) in the model surface layer $(0-150 \mathrm{~m}$ above surface) under two aerosol uptake coefficients: $(a, b)$ $\gamma=0$ (i.e., oxidation only) and (c, d) $\gamma=0.03$ (uptake by sulfuric acid particles). The corresponding zonally averaged vertical distributions of $\tau$ and [DMA] are given in Fig. 3. The oxidation only condition (i.e., no aerosol uptake) leads to a DMA lifetime of $5-10 \mathrm{~h}$ in most parts of lower and middle 
Table 2. Available measurements of MMA, DMA, and TMA concentrations (in pptv) and site information.

\begin{tabular}{|c|c|c|c|c|c|c|}
\hline $\begin{array}{l}\text { Site information } \\
\text { (latitude, longitude) }\end{array}$ & Site type & Observation period & [MMA] & [DMA] & [TMA] & References \\
\hline $\begin{array}{l}\text { A. Gothenburg, Sweden } \\
(57.73,11.97)\end{array}$ & Urban & 24-26 August 1991 & $3.6 \pm 0.9$ & $0.7 \pm 0.5$ & $1.3 \pm 0.6$ & Grönberg et al. (1992a) \\
\hline $\begin{array}{l}\text { B. Lund, Sweden } \\
(55.71,13.19)\end{array}$ & Urban & July 1991 & $16 \pm 5$ & $0.5 \pm 0.3$ & $5.2 \pm 2$ & Grönberg et al. (1992b) \\
\hline $\begin{array}{l}\text { C. Atlanta, GA } \\
(33.85,-84.41)\end{array}$ & Urban & 23 June-25 August 2009 & $<0.2$ & $0.5-2$ & $4-15$ & Hanson et al. (2011) \\
\hline $\begin{array}{l}\text { D. Vallby, Sweden } \\
(59.55,17.13)\end{array}$ & Rural & July 1991 & $10 \pm 3$ & $1.8 \pm 0.6$ & $41 \pm 14$ & Grönberg et al. (1992b) \\
\hline $\begin{array}{l}\text { E. Toronto, ON } \\
(43.67,-79.39)\end{array}$ & Rural & 27 June-5 July 2009 & & $0.2-2.5$ & & VandenBoer et al. (2011) \\
\hline $\begin{array}{l}\text { F. Egbert, ON } \\
(44.23,-79.79)\end{array}$ & $\begin{array}{l}\text { Agricultural and } \\
\text { semiforested }\end{array}$ & 15 October-2 November 2010 & & $6.5 \pm 2.1$ & $1.0-10$ & VandenBoer et al. (2012) \\
\hline $\begin{array}{l}\text { G. Coastal Sweden } \\
\text { (Malmö) } \\
(55.62,13.00)\end{array}$ & Coast & 13-15 August 1991 & $4.4 \pm 1.1$ & $1.1 \pm 0.4$ & $8.7 \pm 3.1$ & Grönberg et al. (1992a) \\
\hline $\begin{array}{l}\text { H. Oahu, Hawaii } \\
(21.48,-158.00)\end{array}$ & Coast & July-August 1985 & $0.2 \pm 0.1$ & $2.0 \pm 1.1$ & $0.7 \pm 0.4$ & Van Neste et al. (1987) \\
\hline $\begin{array}{l}\text { I. Narragansett, Rhode } \\
\text { Island }(41.45,-71.45)\end{array}$ & Coast & & $1.2 \pm 0.3$ & $5.3 \pm 0.9$ & $2.2 \pm 0.9$ & Van Neste et al. (1987) \\
\hline $\begin{array}{l}\text { J. Arabian Sea } \\
(14,63)\end{array}$ & Arabian Sea & 27 August-4 October 1994 & 2.5 & 0.9 & 0.02 & Gibb et al. (1999) \\
\hline $\begin{array}{l}\text { K. Arabian Sea } \\
(14,63)\end{array}$ & Arabian Sea & 16 November-19 December 1994 & 3.2 & 4.4 & 0.2 & Gibb et al. (1999) \\
\hline $\begin{array}{l}\text { L. NW Atlantic } \\
(13.2,-66.1)\end{array}$ & Marine & 28 February 1986 & 0.33 & & & Mopper and Zika (1987) \\
\hline
\end{tabular}

(a) DMA oxidation and uptake lifetime, $\gamma=0$

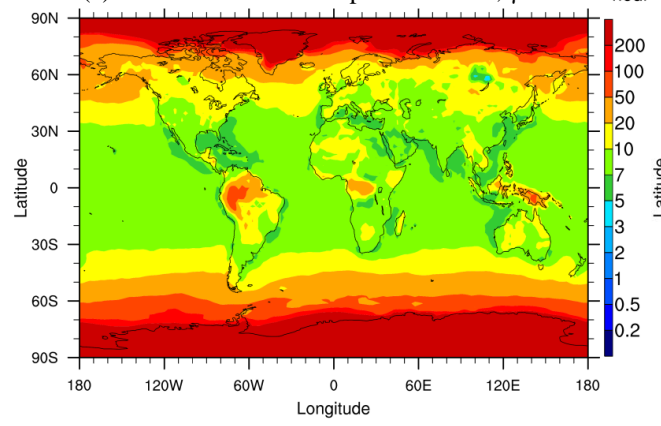

(c) DMA oxidation and uptake lifetime, $\gamma=0.03$ hour

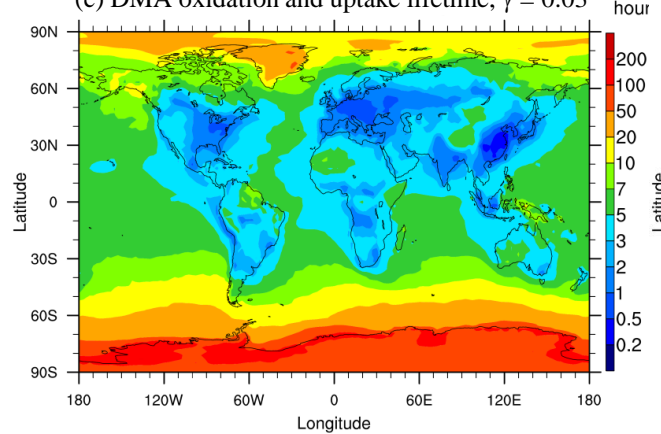

(b) DMA concentration, $\gamma=0$

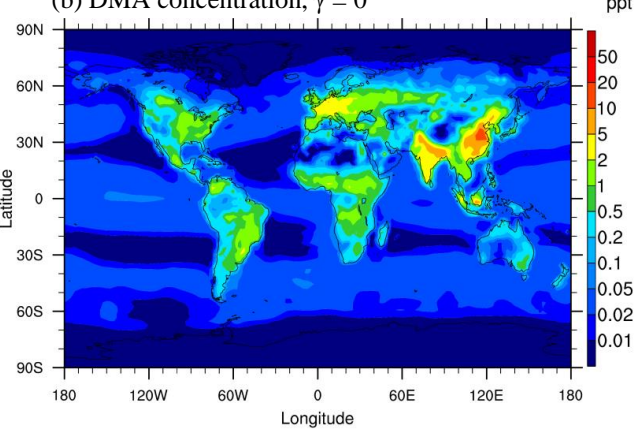

(d) DMA concentration, $\gamma=0.03$

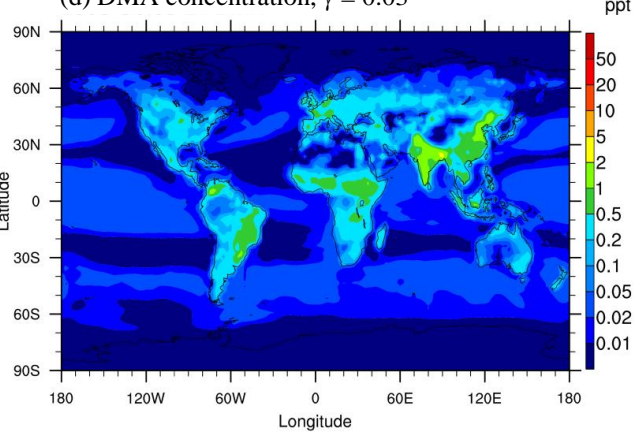

Figure 2. Simulated horizontal distributions of annual mean DMA oxidation and uptake lifetime and concentration ([DMA]) in the model surface layer (0-150 $\mathrm{m}$ above surface) under two aerosol uptake coefficients: (a, b) $\gamma=0$ (i.e., oxidation only) and (c, d) $\gamma=0.03$ (uptake by sulfuric acid particles). 

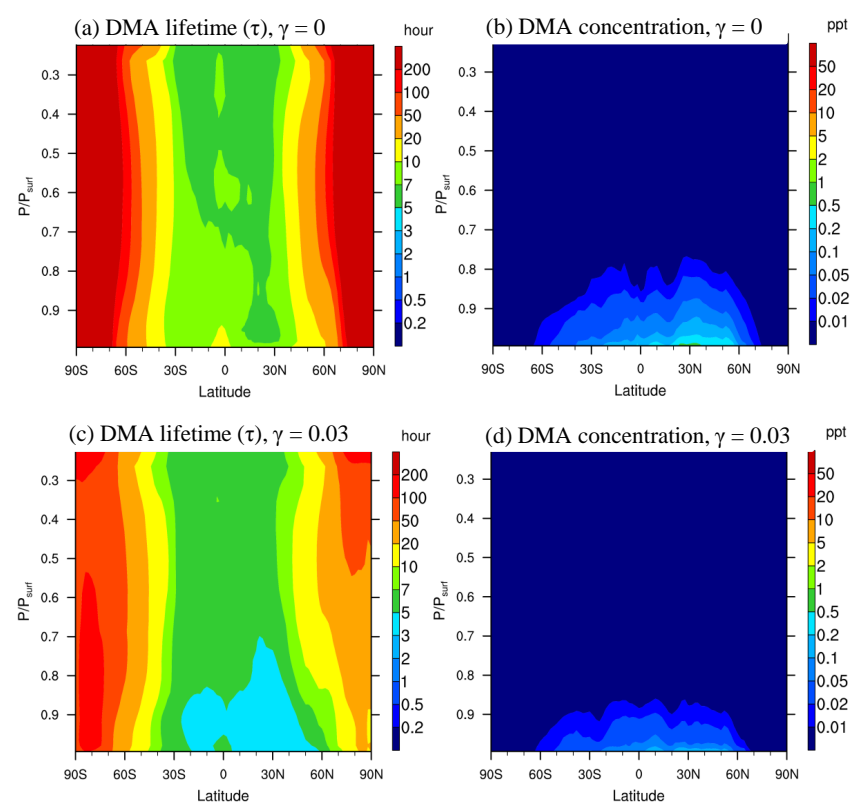

Figure 3. Same as Fig. 2 but for zonally averaged values. Vertical axis is the ratio of pressure $(P)$ at the model layer to the pressure at the surface $\left(P_{\text {surf }}\right)$.

latitude regions, from the surface to the upper troposphere. The oxidation lifetime is relatively long (from 10 to $>200 \mathrm{~h}$ ) over the high latitude regions due to low $\mathrm{OH}$ concentrations there. The aerosol uptake with $\gamma=0.03$ (upper limit, corresponding to the uptake by sulfuric acid particles) shortens the lifetime of DMA by $\sim 30 \%$ over oceans and much more over the major continents, resulting in a DMA lifetime of less than 1-2 $\mathrm{h}$ over central Europe, eastern Asia, and the eastern US (Fig. 2c). Our sensitivity study indicates that $\tau$ values decrease with increasing $\gamma$ when $\gamma>0.001$ but become relatively insensitive to $\gamma$ when $\gamma<0.001$, as oxidation dominates the lifetime under this condition.

As a result of a short lifetime, high values of [DMA] are generally confined to the source regions (Figs. 1, 2b, d). Depending on the uptake coefficients, [DMA] in the surface layer over major continents is in the range of $0.1-2 \mathrm{ppt}$ when $\gamma=0.03$ (Fig. 2d) and 0.2-10 ppt when $\gamma=0$ (Fig. 2b). [DMA] decreases quickly with altitudes, with zonally averaged values dropping below $0.1 \mathrm{ppt}$ a few hundred meters above the surface (Fig. 3b, d). [DMA] over oceans are below $0.05 \mathrm{ppt}$ and these DMA are emitted from marine organisms (Fig. 1) rather than transported from continents. [DMA] over polar regions is below $0.01 \mathrm{ppt}$ (Figs. 2, 3) due to the lack of emissions there (Fig. 1).

The annual mean horizontal and vertical distributions of MMA and TMA concentrations ([MMA], [TMA]) under two $\gamma$ values $(0.03$, and 0$)$ are shown in Figs. 4 and 5. As a result of identical emission spatial distributions (assumed) and short lifetimes, [MMA] and [TMA] have similar spatial distributions as those of [DMA]. [MMA] is generally a factor of $\sim 2.5$ higher than [DMA], reaching $0.2-5 \mathrm{ppt}$ when $\gamma=0.03$ (Fig. 4c) and 0.5-20 ppt when $\gamma=0$ (Fig. 4a) in the surface layer over major continents. While the oxidation rate of MMA is smaller than that of DMA, its deposition velocity is larger. As a result, the [MMA] to [DMA] ratio is close to the ratio of the corresponding global emission fluxes. In contrast, both the oxidation and deposition velocities of TMA are smaller than those of DMA, leading to a larger $[\mathrm{TMA}]$ to $[\mathrm{DMA}]$ ratio $(\sim 8)$ than the corresponding ratio of emission fluxes $(\sim 5)$. [TMA] in the surface layer over major continents reaches 1-10 ppt when $\gamma=0.03$ (Fig. 5c) and 2-50 ppt when $\gamma=0$ (Fig. 5a). Similar to [DMA], [MMA] and [TMA] decrease quickly with altitudes, down to $<0.1 \mathrm{ppt}$ above $\sim 800 \mathrm{mb}$ (Figs. 4b, d, 5b, d).

Figure 6 compares the simulated [MMA], [DMA], and [TMA] with measurements at the sites listed in Table 2 and marked in Fig. 1. The modeling results under four $\gamma$ values $(0.03,0.01,0.001$, and 0$)$ are given. It should be noted that the model results in Figs. 2-5 are annual mean values, while most of the methylamine data are from various field measurements that lasted everywhere from less than 1 day to a few months (Table 2). Owing to large seasonal variations, the model results corresponding to the months of the observations are used for comparisons with observations in Fig. 6. The vertical bars in Fig. 6 (for $\gamma=0.03$ and 0 cases only) define the simulated ranges of monthly mean concentrations of methylamines.

Based on very limited measurements currently available (Table 2), [DMA] in urban areas is smaller than those in rural and coastal areas while [MMA] and [TMA] in these regions do not show a systematic difference. Over the Arabian Sea, measurements of two periods differ by a factor of 5 for [DMA] and by a factor of 10 for [TMA], indicating a large temporal variation in [DMA] and [TMA] concentrations at some locations. It is clear in Fig. 6 that the model predictions of methylamines are substantially lower than the limited observed values available, with normalized mean bias (NMB) ranging from $-57(\gamma=0)$ to $-88 \%(\gamma=0.03)$ for MMA and TMA, and from $-78(\gamma=0)$ to $-93 \%(\gamma=0.03)$ for DMA. [MMA] and [TMA] are relatively closer to observed values, especially when $\gamma<\sim 0.001$. It appears that the simulated [DMA] values are close to the measured values for the three urban sites (A, B, and C) (Fig. 6b).

It is unclear how much the underestimation is associated with the spatial $\left(2^{\circ} \times 2.5^{\circ}\right.$ model grid box with a depth of $\sim 150 \mathrm{~m}$ versus measurements at given sites near the surface) and temporal (model monthly mean versus measurements of a few days to a few weeks) average. The seasonal variations of simulated concentrations of methylamines are generally within a factor of 2-5. As we can see in Figs. 2-5 and Table 1, concentrations of methylamines are roughly proportional to the emission fluxes. Methylamine emissions in certain regions could be much larger, while in other regions much lower than those shown in Fig. 1. Due to the short lifetime of these amines, long-range transport is not important, 
(a) MMA concentration, $\gamma=0$

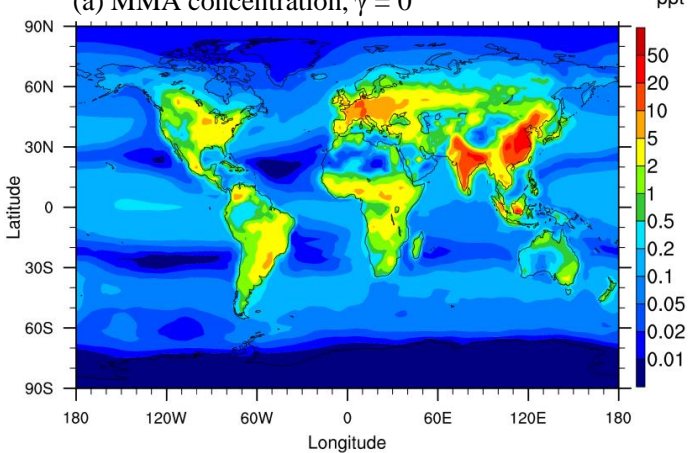

(c) MMA concentration, $\gamma=0.03$

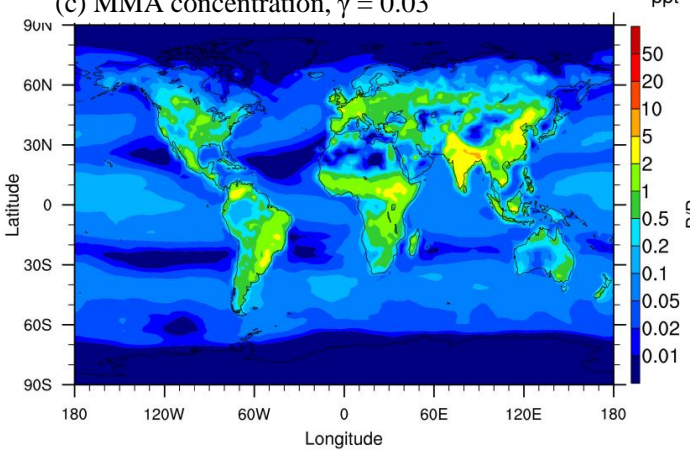

(b) MMA concentration, $\gamma=0$

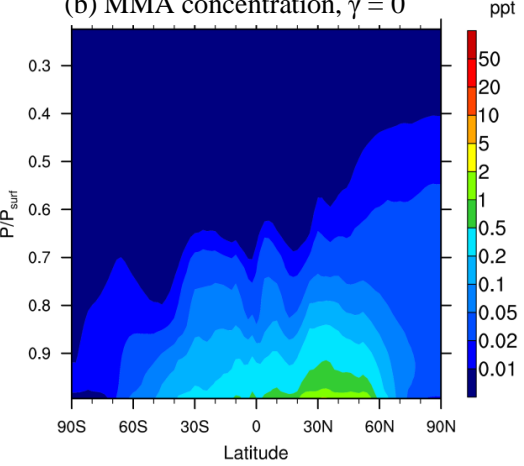

(d) MMA concentration, $\gamma=0.03 \quad \mathrm{ppt}$

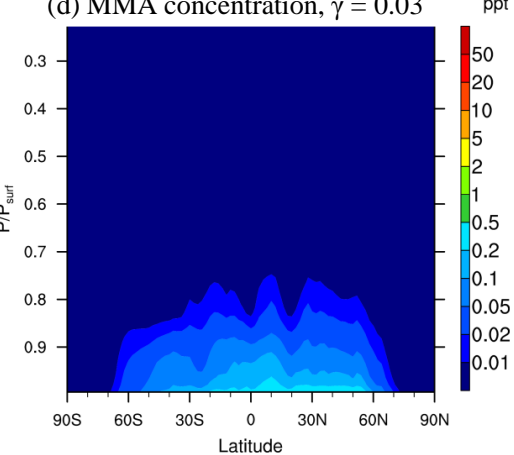

Figure 4. Horizontal distributions of $[\mathrm{MMA}]$ in the surface layer $(\mathbf{a}, \mathbf{c})$ and its zonally averaged values $(\mathbf{b}, \mathbf{d})$ under two different uptake coefficients $(\gamma=0.03$, and 0$)$.

(a) TMA concentration, $\gamma=0$

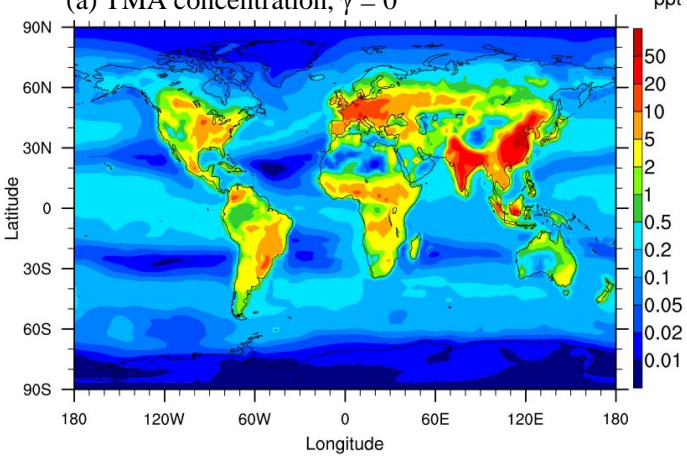

(c) TMA concentration, $\gamma=0.03$

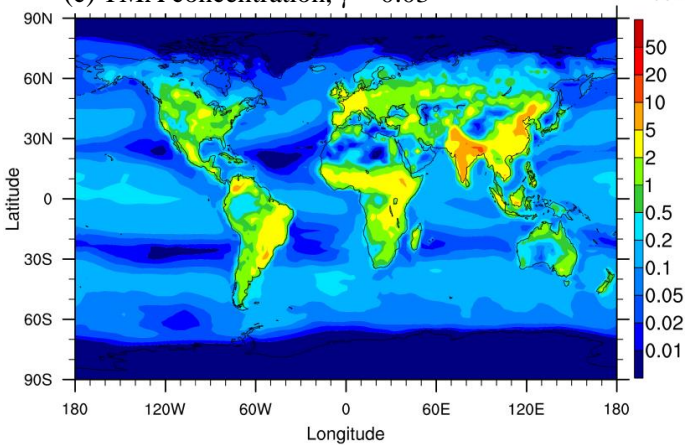

(b) TMA concentration, $\gamma=0$

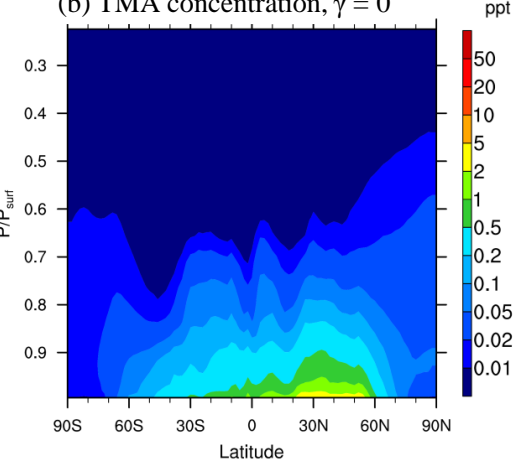

(d) TMA concentration, $\gamma=0.03$

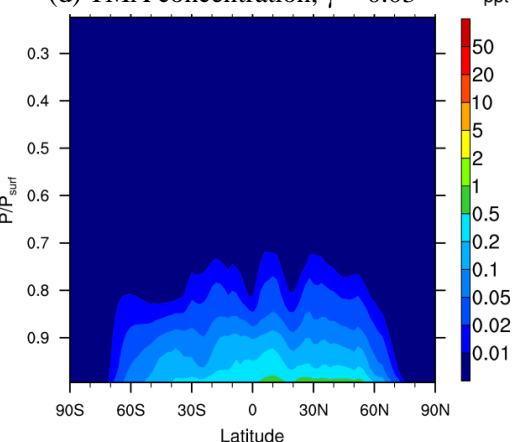

Figure 5. Same as Fig. 4 except for [TMA]. 

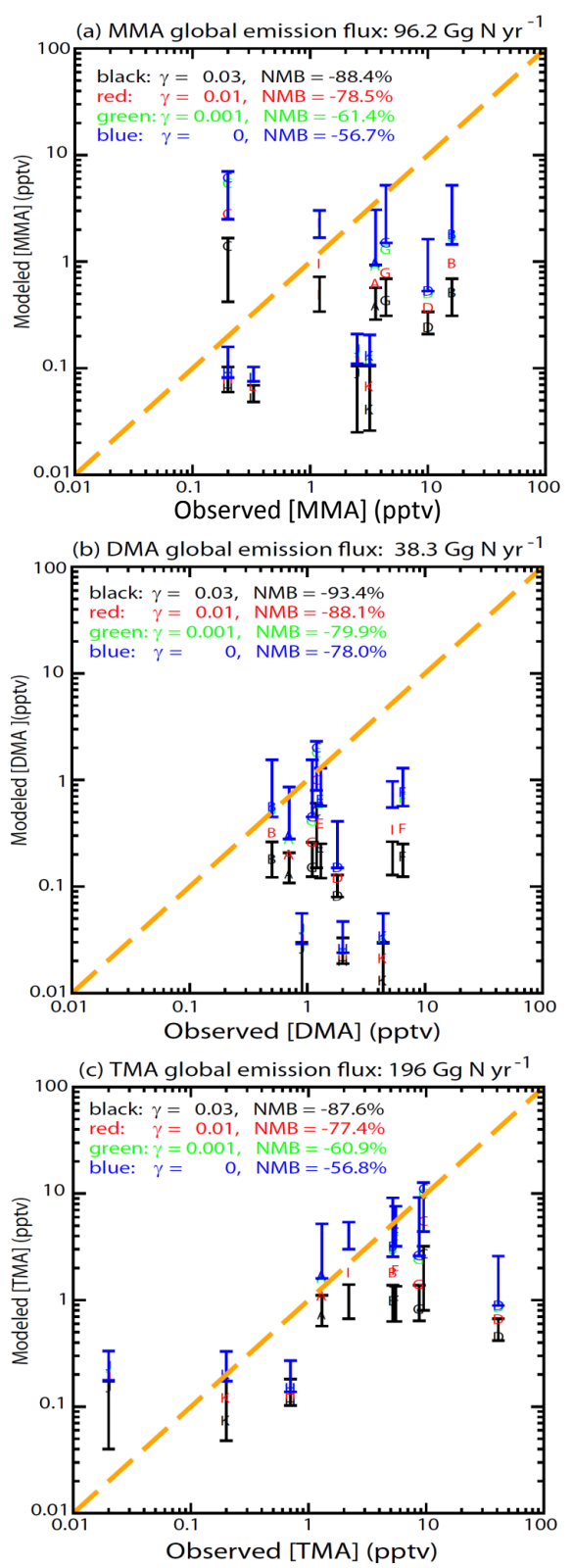

Figure 6. A comparison of simulated and measured [MMA], [DMA], and [TMA] at the sites listed in Table 2 and marked in Fig. 1 by letters. Model results correspond to the months of the observations, and vertical bars define the simulated ranges of monthly mean values.

and thus the observed amine concentrations (together with their lifetime) can be used to estimate the emission strength in the region. If the measurements are representative and reflect the real methylamine concentrations, the underprediction of methylamines by 1-2 orders of magnitude in some sites (Fig. 6) may indicate that the methylamine emissions in these regions are 1-2 orders of magnitude larger than those assumed in this study (Fig. 1, Table 1), at least around the sites of the measurements. Apparently, long-term measure- ments of amines at more locations are needed to evaluate the potential importance of amines.

\section{Summary and discussion}

As a result of the substitution by one or more organic functional groups, amines have a stronger basicity than ammonia and may participate in new particle formation in the atmosphere. To integrate the various processes controlling amine concentrations and understand the concentrations of key amines and their spatiotemporal variations in the atmosphere, we simulate the global distributions of amines in the air with a global chemistry transport model (GEOS-Chem), focusing on methylamines (MMA, DMA, and TMA) in this study.

We showed that gas phase oxidation and aerosol uptakes are dominant sinks for methylamines. The uptake sinks are sensitive to $\gamma$ when $\gamma>\sim 0.001$ and the oxidation becomes more important when $\gamma$ is smaller. The oxidation only (i.e., no aerosol uptake) leads to a methylamine lifetime of 5-10 h in most part of low and middle latitude regions, from the surface to the upper troposphere. The oxidation lifetime is relatively longer $(>10-50 \mathrm{~h})$ over the high latitude regions due to low $\mathrm{OH}$ concentrations there. The aerosol uptake with $\gamma$ of 0.03 reduces the lifetime of methylamines by $\sim 30 \%$ over oceans and much more over the major continents, resulting in methylamine lifetimes as short as $1-2 \mathrm{~h}$ over central Europe, eastern Asia, and eastern US. Depending on $\gamma$ values, [DMA] in the surface layer over major continents is in the range of 0.1-2 ppt when $\gamma=0.03$ and $0.2-10 \mathrm{ppt}$ when $\gamma=0$, and much smaller than over oceans are polar regions $(<0.01-0.05 \mathrm{ppt})$. Compared to [DMA], [MMA] is generally a factor of $\sim 2.5$ higher while [TMA] is a factor of $\sim 8$ higher. Concentrations of methylamines decrease quickly with altitudes, with zonally averaged values dropping below $0.1 \mathrm{ppt}$ above the boundary layer.

The simulated concentrations of methylamines are substantially lower than the limited observed values available, with normalized mean bias (NMB) ranging from -57 $(\gamma=0)$ to $-88 \%(\gamma=0.03)$ for MMA and TMA, and from $-78(\gamma=0)$ to $-93 \%(\gamma=0.03)$ for DMA. The underestimation cannot be explained by the possible uncertainty in the uptake coefficients and long-range transport. The concentrations of methylamines are roughly proportional to their emission fluxes, and thus the model underprediction by 1-2 orders of magnitude at some sites may indicate that the methylamine emissions in these regions are 1-2 orders of magnitude higher than those assumed in this study. It should be noted that methylamine measurements are very limited and subject to large uncertainty as well because of their low concentrations and short lifetime.

Amines have been suggested to be the most likely compound to sequester carbon dioxide and there exists concern about the potential impacts of substantial increases in fu- 
ture amine emissions (Nielsen et al., 2012). Our study indicates that the impact of amine emissions from carbon sequestration is likely to be local rather than global as a result of their short lifetime. The low concentrations of amines away from source regions $(<0.1-1 \mathrm{ppt})$ suggest that the impact of amines on global new particle formation may be quite limited. Nevertheless, amines can exceed a few ppt over the main source regions and thus may substantially enhance new particle formation. It should be noted that about 150 amines have been identified in the atmosphere and amines of different kinds are likely to have different abilities in stabilizing prenucleation clusters. It is important to identify those amines with abundant concentrations in the atmosphere and study their ability in enhancing new particle formation. We would like to emphasize that the present global simulations of methylamines are subject to uncertainties associated with emissions, uptake coefficients, and chemistry. Further laboratory study, field measurement, and numerical modeling are needed to advance our understanding of spatiotemporal distributions of key amines and to evaluate their contributions to new particle formation and growth in the global atmosphere.

Acknowledgements. This study was supported by NASA under grant NNX13AK20G. The GEOS-Chem model is managed by the Atmospheric Chemistry Modeling Group at Harvard University with support from NASA's Atmospheric Chemistry Modeling and Analysis Program.

Edited by: K. Tsigaridis

\section{References}

Almeida, J., Schobesberger, S., Kürten, A., Ortega, I. K., Kupiainen-Määttä, O., Praplan, A. P., Adamov, A., Amorim, A., Bianchi, F., Breitenlechner, M., David, A., Dommen, J., Donahue, N. M., Downard, A., Dunne, E., Duplissy, J., Ehrhart, S., Flagan, R. C., Franchin, A., Guida, R., Hakala, J., Hansel, A., Heinritzi, M., Henschel, H., Jokinen, T., Junninen, H., Kajos, M., Kangasluoma, J., Keskinen, H., Kupc, A., Kurtén, T., Kvashin, A. N., Laaksonen, A., Lehtipalo, K., Leiminger, M., Leppä, J., Loukonen, V., Makhmutov, V., Mathot, S., McGrath, M. J., Nieminen, T., Olenius, T., Onnela, A., Petäjä, T., Riccobono, F., Riipinen, I., Rissanen, M., Rondo, L., Ruuskanen, T., Santos, F. D., Sarnela, N., Schallhart, S., Schnitzhofer, R., Seinfeld, J. H., Simon, M., Sipilä, M., Stozhkov, Y., Stratmann, F., Tomé, A., Tröstl, J., Tsagkogeorgas, G., Vaattovaara, P., Viisanen, Y., Virtanen, A., Vrtala, A., Wagner, P. E., Weingartner, E., Wex, H., Williamson, C., Wimmer D., Ye, P., Yli-Juuti, T., Carslaw, K. S., Kulmala, M., Curtius, J., Baltensperger, U., Worsnop, D. R., Vehkamäki, H., and Kirkby, J.: Molecular understanding of sulphuric acid-amine particle nucleation in the atmosphere, Nature, 502, 359-363, 2013.

Atkinson, R., Baulch, D. L., Cox, R. A., Hampson Jr., R. F., Kerr, J. A., Rossi, M. J., and Troe, J.: Evaluated kinetic, photochemi$\mathrm{cal}$, and heterogeneous data for atmospheric chemistry. V-IUPAC subcommittee on gas kinetic data evaluation for atmospheric chemistry, J. Phys. Chem. Ref. Data, 26, 521-1011, 1997.

Barsanti, K. C. and Pankow, J. F.: Thermodynamics of the formation of atmospheric organic particulate matter by accretion reactionspart 3: carboxylic and dicarboxylic acids, Atmos. Environ., 40, 6676-6686, 2006.

Berndt, T., Stratmann, F., Sipilä, M., Vanhanen, J., Petäjä, T., Mikkilä, J., Grüner, A., Spindler, G., Lee Mauldin III, R., Curtius, J., Kulmala, M., and Heintzenberg, J.: Laboratory study on new particle formation from the reaction $\mathrm{OH}+\mathrm{SO}_{2}$ : influence of experimental conditions, $\mathrm{H}_{2} \mathrm{O}$ vapour, $\mathrm{NH}_{3}$ and the amine tert-butylamine on the overall process, Atmos. Chem. Phys., 10, 7101-7116, doi:10.5194/acp-10-7101-2010, 2010.

Bey, I., Jacob, D. J., Yantosca, R. M., Logan, J. A., Field, B. D., Fiore, A. M., Li, Q., Liu, H. Y., Mickley, L. J., and Schultz M. G.: Global modeling of tropospheric chemistry with assimilated meteorology: Model description and evaluation, J. Geophys. Res., 106, 23073-23095, doi:10.1029/2001JD000807, 2001.

Bouwman, A. F., Lee, D. S., Asman, W. A. H., Dentener, F. J., Van Der Hoek, K. W., and Olivier, J. G. J.: A global high-Â-resolution emission inventory for ammonia, Global Biogeochem. Cy., 11, 561-587, 1997.

Bzdek, B. R., Ridge, D. P., and Johnston, M. V.: Amine reactivity with charged sulfuric acid clusters, Atmos. Chem. Phys., 11, 8735-8743, doi:10.5194/acp-11-8735-2011, 2011.

Carl, S. A. and Crowley, J. N.: Sequential two(blue) photon absorption by $\mathrm{NO}_{2}$ in the presence of $\mathrm{H}_{2}$ as a source of $\mathrm{OH}$ in pulsed photolysis kinetic studies: rate constants for reaction of $\mathrm{OH}$ with $\mathrm{CH}_{3} \mathrm{NH}_{2},\left(\mathrm{CH}_{3}\right)_{2} \mathrm{NH},\left(\mathrm{CH}_{3}\right)_{3} \mathrm{~N}$, and $\mathrm{C}_{2} \mathrm{H}_{5} \mathrm{NH}_{2}$ at $295 \mathrm{~K}$, J. Phys. Chem. A, 102, 8131-8141, 1998.

Chen, M., Titcombe, M., Jiang, J., Kuang, C., Fischer, M. L., Edgerton, E., Eisele, F. L., Siepmann, J. I., Hanson, D. H., Zhao, J., and McMurry, P. H.: Acid-base chemical reaction model for nucleation rates in the polluted boundary layer, Proc. Natl. Acad. Sci., 109, 18713-18718, 2012.

De Haan, D. O., Tolbert, M. A., and Jimenez, J. L.: Atmospheric condensed-phase reactions of glyoxal with methylamine, Geophys. Res. Lett., 36, L11189, 2009.

Erupe, M. E., Viggiano, A. A., and Lee, S.-H.: The effect of trimethylamine on atmospheric nucleation involving $\mathrm{H}_{2} \mathrm{SO}_{4}$, Atmos. Chem. Phys., 11, 4767-4775, doi:10.5194/acp-11-47672011, 2011.

Ge, X. L., Wexler, A. S., and Clegg, S. L.: Atmospheric amines Part I. A review, Atmos. Environ., 45, 524-546, 2011 a.

Ge, X. L., Wexler, A. S., and Clegg, S. L.: Atmospheric amines Part II. Thermodynamic properties and gas/particle partitioning, Atmos. Environ., 45, 561-577, $2011 \mathrm{~b}$.

Gibb, S. W., Mantoura, R. F. C., and Liss, P. S.: Ocean-atmosphere exchange and atmospheric speciation of ammonia and methylamines in the region of the NW Arabian Sea, Global Biogeochem. Cy., 13, 161-178, 1999.

Grönberg, L., Lovkvist, P., and Jönsson, Å, J.: Measurement of aliphatic amines in ambient air and rainwater, Chemosphere, 24, 1533-1540, 1992a.

Grönberg, L., Lovkvist, P., and Jönsson Å, J.: Determination of aliphatic amines in air by membrane enrichment directly coupled to a gas chromatograph, Cromatographia, 33, 77-82, $1992 \mathrm{~b}$.

Hanson, D. R., McMurry, P. H., Jiang, J., Tanner, D., and Huey, L. G.: Ambient pressure proton transfer mass spectrometry: de- 
tection of amines and ammonia, Environ. Sci. Technol., 45, 8881-8888, 2011.

Kurtén, T., Loukonen, V., Vehkamäki, H., and Kulmala, M.: Amines are likely to enhance neutral and ion-induced sulfuric acid-water nucleation in the atmosphere more effectively than ammonia, Atmos. Chem. Phys., 8, 4095-4103, doi:10.5194/acp-8-4095-2008, 2008.

Lee, D. and Wexler, A. S.: Atmospheric amines - Part III: Photochemistry and toxicity, Atmos. Environ., 71, 95-103, 2013.

Lloyd, J. A., Heaton, K. J., and Johnston, M. V.: Reactive uptake of trimethylamine into ammonium nitrate particles, J. Phys. Chem. A, 113, 4840-4843, 2009.

Murphy, S. M., Sorooshian, A., Kroll, J. H., Ng, N. L., Chhabra, P., Tong, C., Surratt, J. D., Knipping, E., Flagan, R. C., and Seinfeld, J. H.: Secondary aerosol formation from atmospheric reactions of aliphatic amines, Atmos. Chem. Phys., 7, 2313-2337, doi:10.5194/acp-7-2313-2007, 2007.

Myriokefalitakis, S., Vignati, E., Tsigaridis ,K., Papadimas, C., Sciare, J., Mihalopoulos, N., Facchini, M. C., Rinaldi, M., Dentener, F. J., Ceburnis, D., Hatzianastasiou, N., O'Dowd, C. D., van Weele, M., and Kanakidou, M.: Global modelling of the oceanic source of organic aerosols, Adv. Meteorol., 2010, 939171, doi:10.1155/2010/939171, 2010.

Nadykto, A. B., Yu, F., Yakovleva, M., Herb, J., and Xu, Y.: Amines in the Earth's Atmosphere: A DFT Study of the Thermochemistry of Pre-Nucleation Clusters, Entropy, 13, 554-569, 2011.

Nadykto, A. B., Herb, J., Yu, F., and Xu, Y.: Enhancement in the production of nucleating clusters due to dimethylamine and large uncertainties in the thermochemistry of amine-enhanced nucleation, Chem. Phys. Lett., 609, 42-49, doi:10.1016/j.cplett.2014.03.036, 2014.

Nielsen, C. J., Herrmann, H., and Weller, C.: Atmospheric chemistry and environmental impact of the use of amines in carbon capture and storage (CCS), Chem. Soc. Rev., 41, 6684-6704, 2012.

Qiu, C. and Zhang, R.: Multiphase chemistry of atmospheric amines, Phys. Chem. Chem. Phys., 15, 5738-5752, 2013.

Qiu, Q., Wang, L., Lal, V., Khalizov, A. F., and Zhang, R.: Heterogeneous Chemistry of Alkylamines on Ammonium Sulfate and Ammonium Bisulfate, Environ. Sci. Technol., 45, 4748-4755, 2011.

Schade, G. W. and Crutzen, P. J.: Emission of aliphatic amines from animal husbandry and their reactions: potential source of $\mathrm{N}_{2} \mathrm{O}$ and HCN, J. Atmos. Chem., 22, 319-346, 1995.

Van Neste, A., Duce, R. A., and Lee, C.: Methylamines in the marine atmosphere, Geophys. Res. Lett., 7, 711-714, 1987.
VandenBoer, T. C., Petroff, A., Markovic, M. Z., and Murphy, J. G.: Size distribution of alkyl amines in continental particulate matter and their online detection in the gas and particle phase, Atmos. Chem. Phys., 11, 4319-4332, doi:10.5194/acp-11-43192011, 2011.

VandenBoer, T. C., Markovic, M. Z., Petroff, A., Czar, M. F., Borduas, N., and Murphy, J. G.: Ion chromatographic separation and quantitation of alkyl methylamines and ethylamines in atmospheric gas and particulate matter using preconcentration and suppressed conductivity detection, J. Chromatogr. A, 1252, 74-83, 2012.

Wang, L., Khalizov, A. F., Zheng, J., Xu, W., Ma, Y., Lal, V., and Zhang, R.: Atmospheric nanoparticle formed from heterogeneous reactions of organics, Nat. Geosci., 3, 238-242, 2010 a.

Wang, L., Lal, V., Khalizov, A. F., and Zhang, R.: Heterogeneous chemistry of alkylamines with sulfuric acid: implications for atmospheric formation of alkylaminium sulfates, Environ. Sci. Technol., 44, 2461-2465, 2010 b.

Williams, B. J., Goldstein, A. H., Kreisberg, N. M., Hering, S. V., Worsnop, D. R., Ulbrich, I. M., Docherty, K. S., and Jimenez, J. L.: Major components of atmospheric organic aerosol in southern California as determined by hourly measurements of source marker compounds, Atmos. Chem. Phys., 10, 11577-11603, doi:10.5194/acp-10-11577-2010, 2010.

Yu, F.: A secondary organic aerosol formation model considering successive oxidation aging and kinetic condensation of organic compounds: global scale implications, Atmos. Chem. Phys., 11, 1083-1099, doi:10.5194/acp-11-1083-2011, 2011.

Yu, F. and Luo, G.: Simulation of particle size distribution with a global aerosol model: contribution of nucleation to aerosol and CCN number concentrations, Atmos. Chem. Phys., 9, 7691-7710, doi:10.5194/acp-9-7691-2009, 2009.

Yu, H., McGraw, R., and Lee S.-H.: Effects of amines on formation of atmospheric sub-3 nm particles and their subsequent growth, Geophys. Res. Lett., 39, L02807, doi:10.1021/2011GL050099, 2012.

Zhao, J., Smith, J. N., Eisele, F. L., Chen, M., Kuang, C., and McMurry, P. H.: Observation of neutral sulfuric acid-amine containing clusters in laboratory and ambient measurements, Atmos. Chem. Phys., 11, 10823-10836, 2011, http://www.atmos-chem-phys.net/11/10823/2011/.

Zollner, J. H., Glasoe, W. A., Panta, B., Carlson, K. K., McMurry, P. H., and Hanson, D. R.: Sulfuric acid nucleation: power dependencies, variation with relative humidity, and effect of bases, Atmos. Chem. Phys., 12, 4399-4411, doi:10.5194/acp-12-43992012, 2012. 